\title{
Parameters affecting the mechanical digging of peanut crops from three different shaped plots
}

\author{
Matheus Anaan de Paula Borba*, Rouverson Pereira da Silva, Adão Felipe dos Santos, André Ferreira \\ Damasceno, Cristiano Zerbato
}

\author{
UNESP - State University Paulista, Jaboticabal, SP, Department of Agricultural Engineering, Access way Prof. Paulo \\ Donato Castellane, without number, 14884-900, São Paulo, Brazil
}

*Corresponding author: matheuspborba@gmail.com

\begin{abstract}
The mechanical harvesting efficiency of agricultural crops affects operational quality and production costs while being dependent on plot shape, operation planning, and management. Therefore, this study evaluated the operational performance of a mechanical tractor-digger set in the digging of peanut crops planted in different shaped plots. The three trapezoidal, triangular and irregular shaped plots had linear lengths of $812 \mathrm{~m}$ (P1), $322 \mathrm{~m}$ (P2) and $248 \mathrm{~m}$ (P3), respectively. The parameters, effective and operational field capacities; digging and management efficiencies; maneuvering and machine downtimes, including the operator personal needs and displacement in the tracks were determined and used to obtain operational efficiency. The yield of the experimental rural area, in Barrinha, SP, is $3200 \mathrm{~kg}$ of peanut $\mathrm{ha}^{-1}$. The experimental design followed the assumptions of statistical process control, and individual value control charts were plotted for each studied variable. The digging operation was monitored and divided into machine downtime, operational time, maneuvering time, and total time. These parameters were then used to calculate the operational capacities and efficiencies of the harvesting operation. It is concluded that plot size and shape affect the operational capacity. Effective and operational capacities are higher in longer plots, lengthwise, while maneuvering times are also shorter. Shorter plots result in digging efficiency losses. Give the best or optimal condition based on results.
\end{abstract}

Keywords: Arachis hypogaea; control charts; mechanized harvest; statistical process control; operational performance.

Abbreviations: $\underline{\mathrm{UCL}}$ - upper control limit. $\underline{\mathrm{LCL}}$ - lower control limit. $\underline{\mathrm{X}}$ : individual-value mean. $\underline{\mathrm{SCL}}-\mathrm{Specified} \mathrm{control} \mathrm{limit.} \underline{\mathrm{GPS}}-$ Global Positioning System. UTM - Universal Transverse of Mercartor. EFC - Effective Field capacity $\left(\right.$ ha $\left.\mathrm{h}^{-1}\right) ; \underline{\mathrm{L} / \mathrm{W}}$ - plot length/width ratio. $\underline{L}$ - plot average length $(\mathrm{m}) \cdot \underline{\mathrm{W}}$ - plot average width $(\mathrm{m}) . \underline{\mathrm{OFC}}$ - Operational Field Capacity $\left(\mathrm{ha} \mathrm{h}^{-1}\right) . \underline{\mathrm{Mt}}-\mathrm{Maneuvering}$ time $(\%)$.

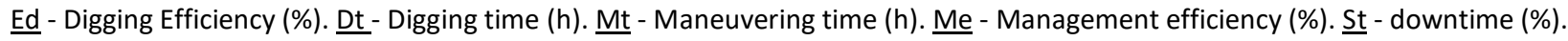

\section{Introduction}

In agriculture, production costs are fundamental to determine the success of the activity. These costs are composed of a management costs, costs with inputs and agricultural operations (MOLIN et al., 2006). In addition, the efficiency of mechanized agricultural operations is a factor that affects the quality of the operations and has a great influence on production costs while being dependent on plot formats and operation planning.

Among these, harvesting has high added value, especially due to the high energy demand and, consequently, the high cost of the required operations. Therefore, studies to collect data on harvesting efficiency, operational capacity, and equipment performance (Paixao et al., 2017) are important since they can help reduce input costs.

The operational capacity of agricultural machines and implements is defined as the amount of work they are able to perform in a unit of time, constituting a measure of the intensity of the work performed in the execution of the operations (Mialhe, 1974). The field efficiency parameter expresses the relation between the effective field capacity of a machine by its theoretical field capacity (ASABE, 2009). Santos et al. (2014) stated that a highly efficient mechanized harvesting operation requires high investments in the management of both, execution and the time spent during execution. However, Paixão et al. (2015) pointed out that a successful harvest requires knowledge on the applicable cultural practices compatible with the production, and one of the factors of great influence is the length and shape of the plots. Linhares et al. (2012) added that factors related to the operator, such as stops for personal hygiene, feeding, and work experience, can influence the operational performance, as well as those inherent to machine factor (displacement speed, maintenance, and obstacles).

The management of field efficiencies can be done in a variety of ways, from the use of simple methods such as clipboard, pen, and timer (Strickland et al., 2001; Cunha et al., 2015) to more sophisticated methods to ensure operation quality and cost reduction. These methods, coupled with quality analysis tools, can help the decisionmaking process.

The quality analysis tools (Statistical Process Control) have been used to monitor the quality of the operation by several authors (Barros and Milan, 2010; Noronha et al., 2011; Cassia et al., 2013; Silva et al., 2013; Ormond et al., 2016; 
Zerbato et al., 2017). However, only Tavares et al. (2015) and Paixão et al. (2017) used SPC as a tool for managing the quality of the agricultural operation coupled with operational performance.

Thus, factors related to operational performance can help the decision-making process during harvesting and, although there is lack of information, plot length and geometry may possibly influence operation quality and management. This study evaluated the effect plot shape on the peanut digging/harvesting operation by monitoring the maneuvers and maneuvering time of the mechanical set (starter/tractor) and analyzed the quality of the operation in the different shaped plot using statistical process control.

\section{Results and discussion}

\section{Analysis of maneuvering times and maneuvers}

Table 1 shows the data for operational and down times and efficiency of mechanized peanut digging. It is noteworthy that the trapezoidal plot had higher operational and effective field capacity compared to the other plots. The plot shape and length allowed to optimize the mechanical peanut digging operation, and because the planted rows were longer (between plot begin and end), the mechanized set worked continuously for a longer period, decreasing maneuvering time and favoring better efficiency ratios.

Table 1 shows that digging efficiency was 17 and $10 \%$ higher in plot 1 compared to 2 and 3, respectively. This higher efficiency of plot 1 can be explained by the longer rows of plot 1 compared to plots 2 and 3, which increased machine operating times and consequently, digging efficiency. It is noteworthy that efficiency is given by the time percentage that the digger-tractor set was effectively operating, minus the maneuvering, maintenance and problem times from the total time.

\section{Analysis of control charts}

The resulting digging efficiencies were $76.1 \%, 63.20 \%$ and $69.10 \%$ in plots 1,2 and 3, respectively. Likewise, Paixão et al. (2015) studied soybean crops planted in trapezoidal and irregular plots and reported efficiencies of $72.70 \%$ and $71.42 \%$, respectively; the similar magnitude results differed by $4.50 \%$ and $3.25 \%$ from this study. On the other hand, Araldi et al. (2013) investigated systematized crops with leveling of the soil surface in level and slope and reported average efficiency of $75.7 \%$ differing by $0.5 \%$ only from the trapezoidal plot efficiency in this study. Reaffirming that the larger area and longer length of plot 1 increased digging times, thereby increasing efficiency. Furthermore, the lowest efficiency obtained for plot 2 may be explained by the longer time spent on maneuvering (19.17\%) and down times (17.65\%).

The management efficiency indicates the influence of time on the digging operation, in which the best result can be verified for plot $3(88.40 \%)$ followed by plots $1(83.90 \%)$ and $2(82.30 \%)$. These results are due to the longer down times in plots 1 and 2 compared to 3 .

Maneuvering time (MT) was higher for plot 2, 19.17\%. The narrow tracks hampered the machine maneuver at the end of this plot and the plot shape hindered the continuous displacement of the tractor-digger set, increasing the need for maneuvers and, consequently, maneuvering time. Araldi et al. (2013) studied an irrigated rice crop and reported that the time consumed for maneuvers represented $11 \%$ of the time of the entire harvesting operation.

Therefore, it can be observed that the trapezoidal shape facilitated the maneuvers compared to the other two plots because the high length/width ratio $(\mathrm{L} / \mathrm{W}=2.50 \mathrm{~m})$ reduced the number of maneuvers.

The shortest machine downtime (11.62\%) was recorded for plot 3 compared to $16.12 \%$ and $17.65 \%$ for plots 1 and 2, respectively. The high values observed for stopping times, regardless of plot size, may be explained by the peculiarities of the peanut harvest, compared to other grains. The peanut harvesting requires frequent equipment stops for cleaning the cutting knives and conveyor belt, and maintenance as well. These shutdowns are fundamental to ensure a better quality of the digging and harvesting processes overall, but they reflect negatively on the operational parameters.

A more conclusive analysis may be reached from the individual control charts of the statistical process control (SPC) for the digging and operational efficiency, maneuvering and downtimes. The control charts in Figure 1a show that plot 1 had only one outlier (point 52, at 28.7\%). The digging efficiency (Fig. 1a) and management efficiency (Fig. 1b) outliers for observations 52 may be explained by the longer downtimes, also leading to the outlier observed in Figure $1 \mathrm{~d}$. These longer downtimes were entirely due to the maintenance/cleaning times and equipment repairment such as inverting fingers, conveyor belts, and knives. The maneuvering time outliers in the individual control charts did not result in outliers for digging and management efficiencies.

Figure 2a shows the control charts for plot 2. Digging efficiency had eight outliers (observations 18, 24, 35, 36, 37, 38,39 and 70 ) probably caused by the long maneuvering time (observations $18,35,36,37,38$ and 70 ) resulting from the narrow tractor tracks in this plot. Meanwhile, the other two outliers (24 and 35) were influenced by the longer downtime caused by the machine operator. Management efficiency (Fig. 2b) had five outliers (24, 25, 39, 46 and 70) below the lower control limit that possibly resulted from special causes, the so-called 6Ms (manpower, mother nature/environment, machine, method, materials, and measurements), especially manpower in this case.

The control charts for plot 3 (Fig. 3) also show a few outliers. The digging (Fig. 3a) and management (Fig. 3b) efficiencies had an outlier in observation 15 , also explained by the special causes, especially manpower. The poor quality of observations 41 and 105 in the digging efficiency (Fig. 3a) control chart is possibly due to the high maneuvering time, while 63, 74 were due to discrepancies between maintenance times (machine) and manpower. The management efficiency differed from the others due to the excessive machine downtime, also explained by the special causes, such as machine maintenance and jamming, and operator stops (manpower). The high number of outliers above the upper limit seen on the maneuvering time chart was caused by the irregular plot shape that made difficult to define the tractor tracks while track shape and different sizes also hampered maneuvering, throughout the digging operation. 
Table 1. Results for the effective and operation field capacities, digging and management efficiencies, maneuvering and downtime and length/width ratio for different shaped plots.

\begin{tabular}{lccc}
\hline \multirow{2}{*}{ Variables } & \multicolumn{3}{c}{ Plots } \\
\cline { 2 - 4 } & Trapezoidal (1) & Triangular (2) & Irregular (3) \\
\hline EFC $\left(\mathrm{ha} \mathrm{h}^{-1}\right.$ ) & 1.15 & 1.00 & 0.92 \\
OFC $\left(\mathrm{ha} \mathrm{h}^{-1}\right.$ ) & 0.87 & 0.63 & 0.63 \\
DE (\%) & 76.10 & 63.20 & 69.10 \\
ME (\%) & 83.90 & 82.30 & 88.40 \\
MT (\%) & 7.75 & 19.17 & 19.33 \\
ST (\%) & 16.12 & 17.65 & 11.62 \\
L / W & 2.50 & 1.44 & 0.79 \\
\hline
\end{tabular}

EFC - Effective field capacity; OFC - operational field capacity; DE - digging efficiency; ME - management efficiency; MT - maneuvering time; ST - downtime; L/W - length/width ratio.

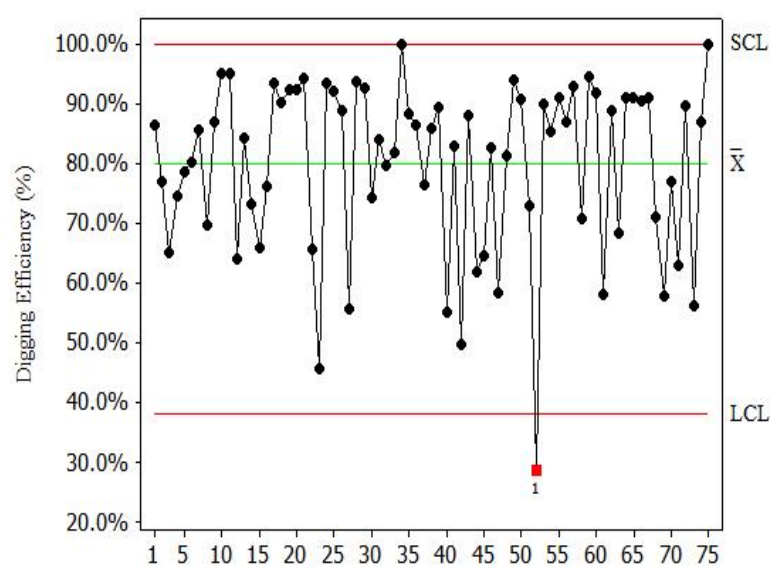

(a)

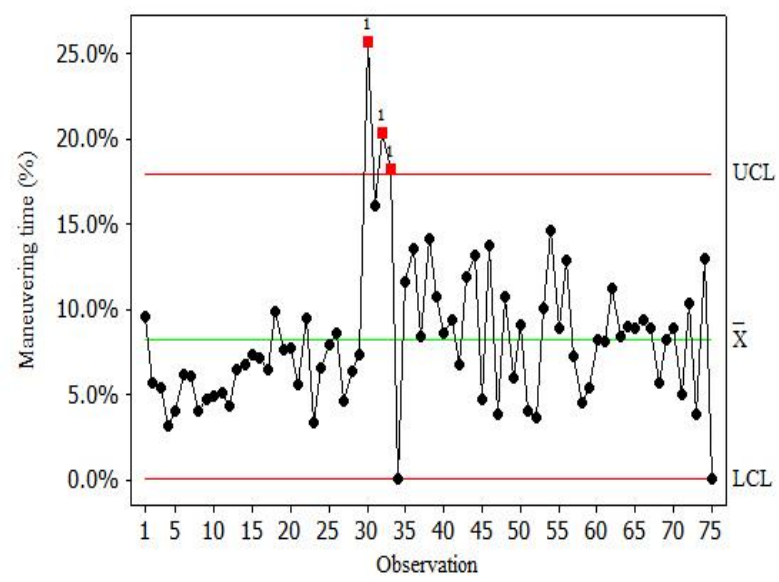

(c)

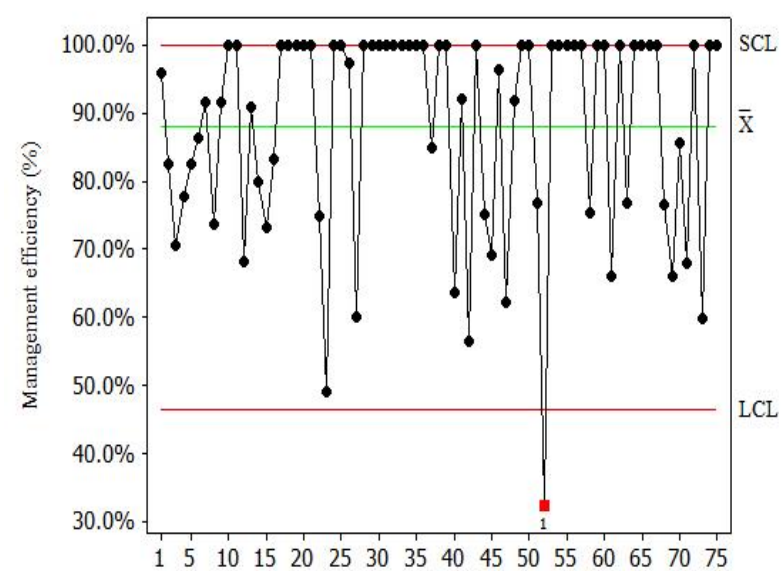

(b)

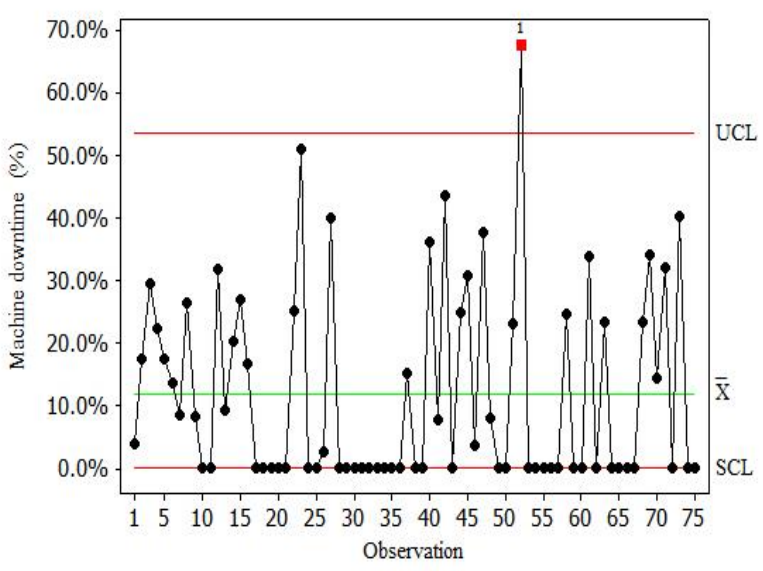

(d)

Fig 1. Individual control charts of plot 1 for (a) digging efficiency; (B) management efficiency; (C) Maneuvering time; and, (D) downtime.

Table 2. Dimensions of the plots.

\begin{tabular}{llll}
\hline Plots & Shape & Area (ha) & Rows $(\mathrm{m})$ \\
\hline 1 & Trapezoidal & 26.35 & 812.2 \\
2 & Triangular & 7.18 & 322.06 \\
3 & Irregular & 7.85 & 248.41 \\
\hline
\end{tabular}




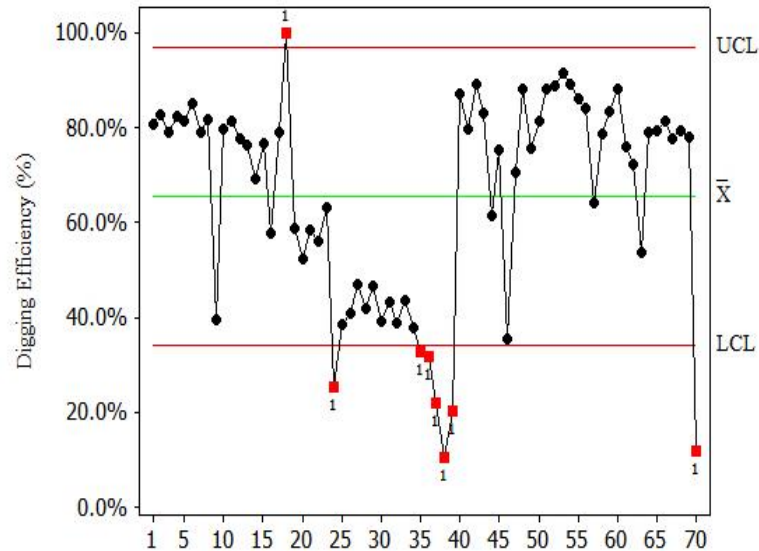

(a)

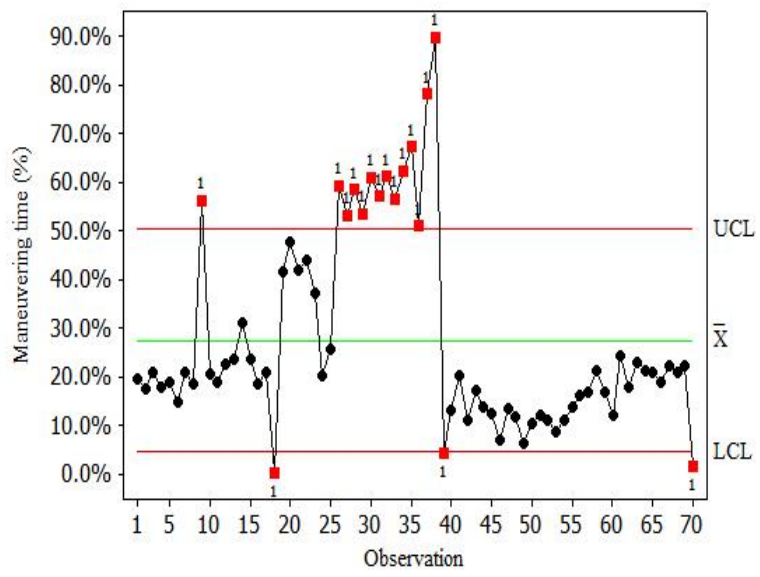

(c)

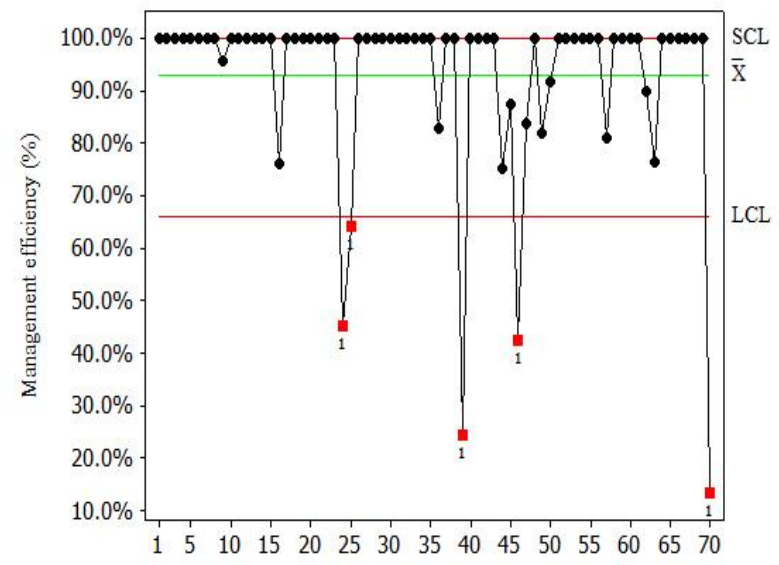

(b)

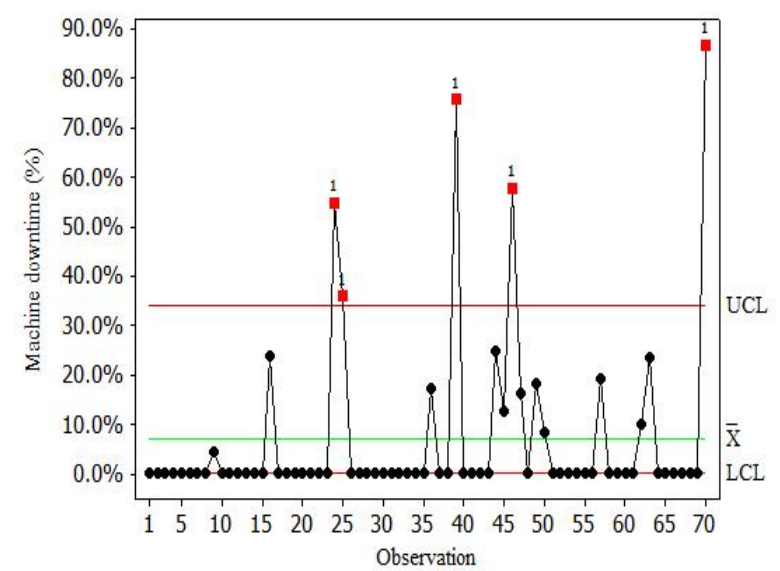

(d)

Fig 2. Individual control charts of plot 2 for (a) digging efficiency; (B) management efficiency; (C) Maneuvering time; and, (D) downtime.

Table 3. Division and characterization of the activities performed in the mechanical peanut digging/harvesting.

\begin{tabular}{ll}
\hline Times & Description \\
\hline \multirow{3}{*}{ Operational time } & $\begin{array}{l}\text { Time required for peanut digging operation, measured as the time } \\
\text { interval that the digger-inverter platform remained under the } \\
\text { ground digging the plants to form the windrows. }\end{array}$ \\
\hline \multirow{3}{*}{ Maneuvering time } & $\begin{array}{l}\text { Time required for maneuvering the digger-inverter set between } \\
\text { rows, measured as the time interval elapsed between the lifting of } \\
\text { the platform at the end of one row until it is repositioned on the } \\
\text { ground at the beginning of another row. }\end{array}$ \\
\hline Machine downtime & $\begin{array}{l}\text { Time spent repairing and cleaning the winders ("carambolas"), } \\
\text { conveyor belt and equipment knives (maintenance time) plus the } \\
\text { time required to solve unforeseen problems, such as machine jam } \\
\text { and stops for the operator personal needs (problem time). }\end{array}$ \\
\hline
\end{tabular}

\section{Materials and methods}

\section{Experimental characteristics}

The experiment was performed in a rural area near the $21^{\circ} 11^{\prime} \mathrm{S}$ and $48^{\circ} 12^{\prime} \mathrm{W}$ geodesic coordinates, at $492 \mathrm{~m}$ altitude. The soil of the area has a clay texture, with $42 \%$ clay, $20 \%$ silt, and $37 \%$ total sand (EMBRAPA, 2013). The climate is Aw tropical according to Peel et al. (2007).

The area was planted with the peanut variety, Runner IAC 886; spaced $0.9 \mathrm{~m}$ between rows; 21 seeds $\mathrm{m}^{-1}$ sowing density; and $3200 \mathrm{~kg} \mathrm{ha}^{-1}$ average yield per plot, while average total losses (visible and invisible losses) were assumed as $4 \%$ of productivity for all three plots.

\section{Equipment}

Peanut digging lasted two days and was performed by the BM 110, 4x2 TDA tractor with $80.96 \mathrm{~kW}$ (110 hp) power and equipped with AIA-Santal II digger-inverter. The set traveled at $4.5 \mathrm{~km} \mathrm{~h}^{-1}$ displacement speed, $1600 \mathrm{rpm}$ engine rotation, reaching $540 \mathrm{rpm}$ in the TDP, following the manufacturer recommendations. 


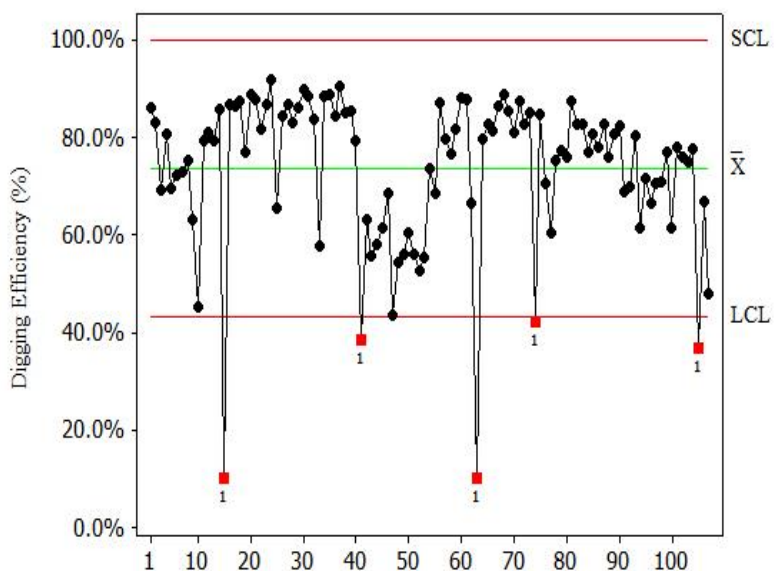

(a)

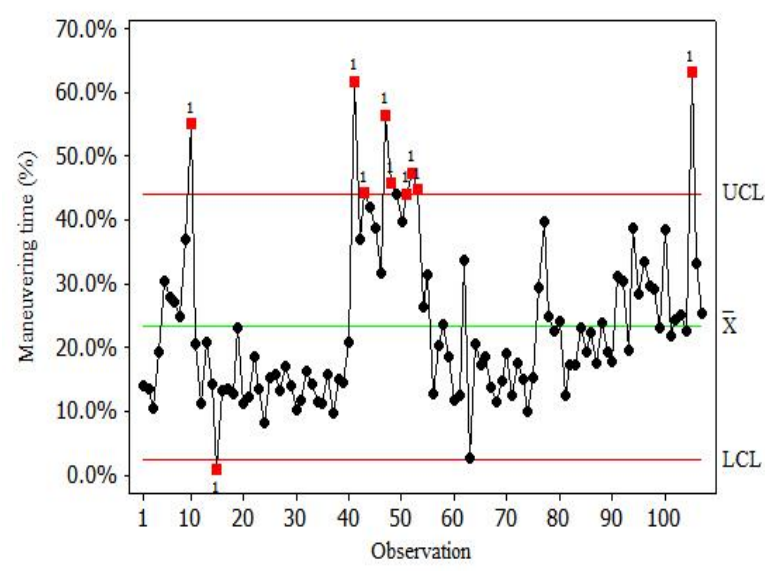

(c)

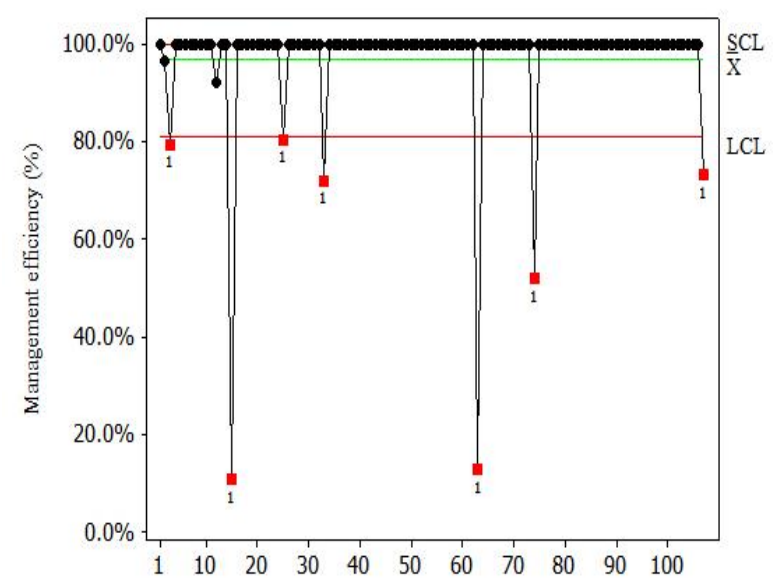

(b)

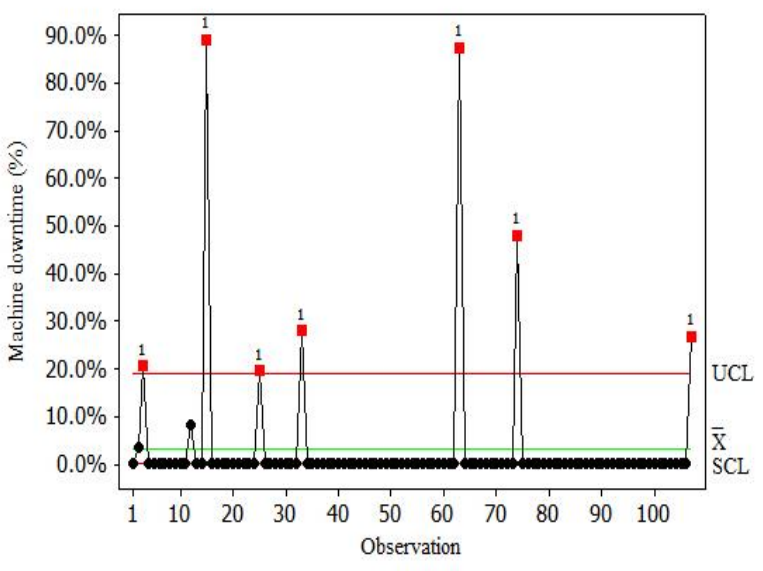

(d)

Fig 3. Individual control charts of plot 3 for (a) digging efficiency; (B) management efficiency; (C) Maneuvering time; and, (D) downtime.

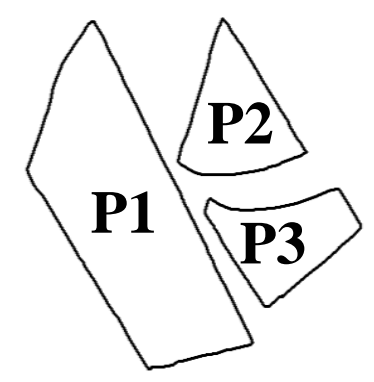

Fig 4. Map of the experimental area.

\section{Performed evaluations}

The experimental design followed the premises of statistical process control, where the times were measured in each plot so that each line traveled by the mechanical set represented a sampling point in the individual control charts. The time interval required for operation, maneuver and stops for maintenance and other problems were measured for each plot.

Table 2 shows the characteristics of the three evaluated plots, the trapezoidal plot 1 , the triangular plot 2 , and the irregular plot 3 (Figure 4).

The area was mapped using a Garmin GPS receiver, eTrex ${ }^{\circledR}$ model (metric precision). The coordinates were recorded in the UTM Cartesian coordinate system (Universal Transverse of Mercator).

The data were collected in 41,70 and 108 rows in plots 1,2 and 3 , respectively, given that the working width of the digger-inverter is $1.80 \mathrm{~m}$.

The operational and down times, described in Table 3, were measured during the operation using a stopwatch, written down and classified as operational times, maneuvering and machine downtimes (maintenance and problems).

Subsequently, total, operating, and maneuvering times, downtime and plot length/width ratio data were used to calculate field efficiency (ASABE EP 496.3, 2011), time efficiency and capabilities (Mialhe, 1974). The effective field capacity and plot length/width ratio were calculated by 
equations 1 and 2, respectively, adapted from Mialhe (1974).

$$
\mathrm{EFC}=\frac{\text { Worked area }}{\text { Operating time }}
$$

where:

EFC: Effective Field capacity $\left(\right.$ ha $\mathrm{h}^{-1}$ ).

$C / L=\frac{L}{W}$

where:

L/W: plot length/width ratio;

L: plot average length $(\mathrm{m})$; and,

W: plot average width $(\mathrm{m})$.

Likewise, operational field capacity and maneuvering time were calculated by equations 3 and 4, respectively, adapted from Mialhe (1996).

$$
\text { OFC }=\frac{\text { Worked area }}{\text { Total time }}
$$

where:

OFC: Operational Field Capacity $\left(\right.$ ha $\left.^{-1}\right)$.

$$
\operatorname{Mt}(\%)=\left\{\frac{\text { Mt }}{D t+M t+M a i n T+S t}\right\} \times 100
$$

(4)

where:

Mt: Maneuvering time (\%).

Equations 5 and 6 were used to calculate digging efficiency (Ed) and management efficiency (Me) following the methodology described in Asabe EP 496.3 (2011):

$\operatorname{Ed}(\%)=\left\{\frac{\mathrm{Dt}}{\mathrm{Dt}+\mathrm{Mt}+\mathrm{St}}\right\} \times 100$

where:

Ed: Digging Efficiency (\%);

Dt: Digging time (h);

Mt: Maneuvering time (h);

St: Machine downtime $(\mathrm{h})$.

$$
\operatorname{Me}(\%)=\left\{\frac{\mathrm{Dt}+\mathrm{Mt}}{\mathrm{Dt}+\mathrm{Mt}+\mathrm{St}}\right\} \times 100
$$

where:

Me: Management efficiency (\%).

Equation 7 was used to obtain downtime (\%) given by maintenance plus problem times.

$$
\text { St }(\%)=\left\{\frac{\mathrm{St}}{\mathrm{Dt}+\mathrm{Mt}+\mathrm{St}}\right\} \times 100
$$

where:

St: downtime (\%).

\section{Analysis of results}

The center line in the individual control chart represents the overall mean while the lines above and below the mean are the upper and lower control limits (UCL and $L C L$ ), respectively. The $U C L$ and $L C L$ are given by the mean plus and minus three times the standard deviation, respectively. The process is considered stable when the collected data are within the upper and lower control limits whereas the data outside the control limits are outliers, indicating that the process is unstable. Process instability might be explained by the $6 \mathrm{Ms}$ (machine, manpower, measurement, method, materials and mother nature/environment) (MONTGOMERY, 2009).
Voltarelli et al. (2015) stated that control charts are generally used to detect possible external variations to the process; to force operational management by creating an improvement plan; and, to infer the capacity and process limits. The unstable or out-of-control process can be explained by the Ishikawa diagram of cause-effect or "fishbone", attributing these instabilities to the $6 \mathrm{Ms}$ (machine, manpower, measurement, method, materials and mother nature/environment).

Charts plotting percentage values resulting from the standard deviation calculation may have control limits below and above the 0 to $100 \%$ interval. Therefore, specific control limits (SCL) were used to limit, when necessary, the values of the control charts to the 0 and $100 \%$ interval.

\section{Conclusion}

The plot shape affects the performance and quality of peanut mechanical harvesting. Furthermore, plot 1 has the best results regarding effective field and operational capacities and maneuvering time. Plot 2 has the lowest digging/harvesting and management efficiencies. The SPC control charts show that plot 1 has the best results for the digging and management efficiencies and the lowest number of outliers, indicating an overall better quality process.

\section{References}

Araldi PF, Schlosser JF, Frantz UG, Ribas RL, Santos PM (2013) Operational efficiency in mechanized harvesting in irrigated rice crops. Ciência Rural. 43(3): 445-451.

Asabe (AMERICAN SOCIETY OF AGRICULTURAL BIOLOGICAL ENGINEERS). ASABE EP 496 JUN11: Agricultural machinery management data. In: ASABE Standards 2011: standards engineering practices data. St. Joseph, 2011. p.6.

Barros FF, Milan M (2010) Operational quality of sugarcane plantation. Bragantia. 69(1):221-229.

Cassia MT, Silva RP, Chioderolli CA, Noronha RHF, Santos EP (2013) Quality of mechanized coffee harvesting in circular planting system. Ciência Rural. 43(1):28-34.

Cunha JP, Silva FM, Dias Reba (2016) Efficiency of field in different mechanized operations in coffee cultivation. Coffee Science.11(1):76-86.

Embrapa - EMPRESA BRASILEIRA DE PESQUISA AGROPECUÁRIA (2013). Brazilian system of soil classification. 3.ed. Brasília. 353 p.

Linhares M, Sette Júnior CR, Campos F, Yamaji FM (2012) Efficiency and operational performance of harvester and forwarder machines in forest harvesting. Pesquisa Agropecuária Tropical. 42(2):212-219.

Mialhe LG (1974) Manual of agricultural mechanization. São Paulo: Agronomic Publishing Ceres. $301 \mathrm{p}$.

Mialhe LG (1996) Used farm equipment: test and certification. Piracicaba: CNPq-PADCT/TIB; FEALQ, p. $600-$ 650.

Molin JP, Milan M, Nesrallah MGT, Castro CN, Gimenez LM (2006) Use of georeferenced data in the determination of performance parameters in mechanized harvesting. Engenharia Agrícola. 26(3): 759-767.

Montgomery, DC (2009) Control charts for variables. In: MONTGOMERY D.C. (ed) Introduction to statistical quality control. 6rd edn. Wiley, New York. 226-268. 
Noronha RHF, Silva RP, Chioderoli CA, Santos EP, Cassia MT (2011) Statistical control applied to the day and night mechanized harvesting process of sugarcane. Bragantia. 70(4):931-938.

Ormond ATS, Voltarelli MA, Paixão CSS, Gírio LAS, Zerbato C, Silva RP (2015) Agronomic characteristics of soybean in conventional and cross sowing. Revista Agro@mbiente Online. 9(4):414-422.

Paixão CSS, Voltarelli MA, Silva RP, Tavares TO (2015) Operational capacity in mechanized soybean harvesting. In. SILVA, R.P.; VOLTARELLI, M.A.; CASSIA, M.T. Quality control in mechanized agricultural operations. Jaboticabal, São Paulo. Brazilian Association of Agricultural Engineering. 125-135.

Paixão CSS, Alcântara AS, Voltarelli MA, Tavares TO, Silva RP (2017) Monitoring of soybean mechanical harvesting as a function of plot shapes. Revista Engenharia Agrícola. 37(4):689-698.

Peel M, Finlayson B, Mcmahon T (2007) Updated world map of the Koppen-Geiger climate classification. Hydrol Earth Syst Sc. 11:1633-1644.

Peixoto CP, Gonçalves JA, Peixoto MFSP, Carmo DO (2008) Agronomic characteristics and peanut yield at different spacings and sowing times in the concave of Bahia. Bragantia. 67(3): 673-684.

Santos EP, Silva RP, Bertonha RS, Noronha RHF, Zerbato C (2013) Productivity and losses of peanuts in five different starter dates. Revista Ciência Agronômica. 44(4): 695-702.

Santos NB, Cavalcante DS, Fernandes HC, Gadanha JUNIOR CD (2014) Simulation of the field efficiency of mechanized harvesting of sugarcane (Saccharum spp.). Energia na Agricultura. 29(1): 09-13.

Silva RP, Cassia MT, Voltarelli MA, Compagnon AM, Furlani CEA. Quality of mechanized bean harvesting in two soil tillage systems. Revista Ciência Agronômica.44(1):61-69.

Strickland, RM. Extracting machine perfomance information from site-specific grain yield data to enhance crop production management practices. 2001. Disponível em: $<$ https://www.

agriculture.purdue.edu/SSMC/newsletters/july2001f. htm>. Acesso em: 15 abr. 2014.

Tavares TO, Santinato F, Silva RP, Voltarelli MA, Paixão CSS, Santinato R (2015) Quality of mechanized coffee gathering. Coffee Science. 10(4):455-463.

Voltarelli MA, Silva RP, Cassia MT, Ortiz DF, Torres LS (2015) Quality of the basal cut of sugarcane using three models of knives. Engenharia Agrícola. 35(3): 528-541.

Voltarelli MA, Silva RP, Zerbato C, Paixão CSS, Tavares TO (2015) Monitoring of mechanical sugarcane harvesting through control charts. Engenharia Agrícola. 35(6): 10791092.

Zerbato C, Furlani CEA, Silva RP, Voltarelli MA, Santos AF (2017) Statistical control of processes aplied for peanut mechanical digging in soil textural classes. Revista Engenharia Agrícola. 37(2):315-322.

Zerbato C, Silva VFA, Torres LS, Silva RP, Furlani CEA (2014) Peanut mechanized digging regarding to plant population and soil water level. Revista Brasileira de Engenharia Agrícola e Ambiental. 18(4): 459-465. 